\title{
ANALISIS FAKTOR PENDORONG DAN PENARIK WISATAWAN BERKUNJUNG KE LABUAN BAJO, KABUPATEN MANGGARAI BARAT
}

\author{
Susana Santi Jaimun 1 , I Wayan Suardana ${ }^{2}$, I Ketut Suwena ${ }^{3}$ \\ Email: shantijaimun0604@gmail.com ${ }^{1}$, suar.dana@yahoo.co.id ${ }^{2}$, suwenaketut31@gmail.com ${ }^{3}$ \\ 1,2,3Program Studi Sarjana Industri Perjalanan Wisata, Fakultas Pariwista, Universitas Udayana
}

\begin{abstract}
Labuan Bajo is one of the 10 priority destinations, which the Govermment is currenty focusing on in developing both its attraction and facilities that support the sustainability of the tourism activities. To support this goverment policy, Labuan Bajo regional tourism actors must understand the needs of tourists and develop and maintain existing touris attractions, so that they can attract torists to visit. The purposes of this research are to anlyses the push and pull factors that motivate the tourist traveled to Labuan Bajo. The sampling technique used purposive sampling by distributing 100 questionnaires via google form to tourist who have visited Labuan Bajo. The data was used the likert scale model questionnaire which was calibated using the coefficient 0,5 . The data analysis technique is descriptive quantitative using factor analysis and processed by the application SPSS 23.0 for windows. The data collection technique are interviews, observation, literature and questionnaires. The results showed were four factors that push tourists to visit Labuan Bajo, namely Escape, novelty, prestige, and looking for luxurious and exclusive places and seven factors that pull tourists to visit Labuan Bajo, namely hunting, culture and history, budget, facilities, ease to travel. , affordable food and beverage prices as well as cleanliness and safety of facilities. The dominant factor that push tourists to visit Labuan Bajo is the escape factor with an eigenvalue 2,029 with a diversity of indicators of $16,912 \%$, while the dominant factor that pull tourists to visit Labuan Bajo is hunting with an eigenvalue of 2,554 and a diversity of indicators of $13,441 \%$.
\end{abstract}

Abstrak: Labuan Bajo merupakan salah satu dari 10 destinasi prioritas, yang sedang difokuskan Pemeritah dalam pengembangannya, baik dari daya tarik wisata serta fasilitas yang mendukung keberlangsungan kegiatan pariwisata tersebut. Dalam mendukung kegiatan kegiatan Pemerintah tersebut pelaku pariwisata Labuan Bajo harus memahami motivasi yang mendorong dan menarik wisatawan, kebutuhan wisatawan serta mengembang dan menjaga daya tarik wisata yang ada. Sehingga dapat menarik wisatawan untuk berkunjung. Tujuan penelitian ini untuk mengetahui faktor pendorong dan penarik wisatawan berkunjung ke Lauan Bajo. Teknik penentuan sampel menggunakan purposive sampling dengan menyebarkan 100 kuesioner melalaui google form. Data yang digunakan kuesioner model skala likert yang dikalibrasikan memakai uji validitas dan uji reliabilitas dihitung dengan memakai koifisien alpha caonbach 0,5. Teknik analisis data adalah deskriptif kuantitatif dengan menggunakan analisisi faktor dan diolah dengan aplikasi SPSS 23.0 for windows. Teknik pengumpulan data dengan cara wawancara, observasi, kepustakaan dan kuesioner. Hasil menunjukan bahwa terdapat empat faktor yang mendorong wisatawan berkunjung ke Labuan Bajo yaitu Escape, Novelty, Prestige dan mencarai tempat mewah/eksklusif. Sedangkan terdapat 7 faktor yang menarik wisatawan berkunjung ke Labuan Bajo yaitu, Hunting, culture and history, budget, facilities, ease to travel, harga makanan dan minuman terjangkau serta kebersihan dan keamanan fasilitas. Faktor dominan yang mendorong wisatawan berkunjung ke Labuan Bajo adalah faktor escape dengan eigenvalue 2.029 dengan keberagaman indikator sebesar $16.912 \%$, sedangkan faktor dominan yang menarik wisatawan berkunjung ke Labuan Bajo adalah hunting dengan eigenvalue 2.554 serta keberagaman indikator sebesar $13.441 \%$.

Keywords: labuan bajo, tourist, push factor, pull factor. 


\section{PENDAHULUAN}

Sejak Presiden Joko Widodo menetapkan sektor pariwisata sebagai sektor unggulan pembangunan nasional, perkembangan pariwisata di Indonesia semakin maju. Hal ini dapat dilihat dalam branding wonderful Indonesia, dimana posisi pariwisata Indonesia di mata dunia berada pada peringkat ke-50 tahun 2015. Laporan resmi world economic forum menyebutkan bahwa Indonesia berhasil naik delapan peringkat yakni posisi 42 pada periode 6 April 2017, yang sebelumnnya diperingkat 70 dari 141 negara tercatat tahun 2013. Berkembangnya sektor pariwisata disuatu negara atau daerah akan menarik sektor lain, karena produk-produknya diperlukan menunjang industri pariwisata. Oleh karena itu, pemerintah daerah harus mengupayakan untuk mengembangkan daya tarik wisata yang ada sehingga dapat menarik wisatawan untuk berkunjung ke suatu daya tarik wisata tersebut. Banyak faktor yang memotivasi orang melakukan perjalanan wisata. Menurut Yoon dan Uysal (2005), motivasi pendorong lebih berkaitan dengan aspek emosional internal sedangkan motivasi penarik berhubungan dengan aspek eksternal situaional atau kognitif. Disisi lain, faktor pendorong (push factor) adalah keinginan intrinsik dari wisatawan, seperti keinginan untuk melarikan diri dari rutinitas, istirahat dan relaksasi, kesehatan dan kebugaran, petualang, prestise dan interaksi sosial. Sedangkan, faktor penarik (pull factor) mencakup faktor yang muncul sebagai akaibat dari daya tarik destinasi wisata. Misalnya, pantai, fasilitas rekreasi dan tempat bersejarah, persepsi wisatawan dan harapan seperti sesuatu yang baru, keuntungan yang diharapkan serta citra pemasaran destinasi wisata tersebut, (Yoon dan Uysal, 2005)

Kota Labuan Bajo merupakan Ibu kota Kabupaten Manggarai Barat. Letak geografis Labuan Bajo berada di bagian Barat Pulau Flores, menjadikan Labuan Bajo sebagai pintu masuk bagian Barat Pulau Flores. Labuan Bajo dikelilingi oleh gugus pulau kecil dengan perairan lautnya. Pemandangan pantai telah manjadi daya tarik baru di dunia pariwisata dan sangat potensial diminati wisatawan. Kekuatan Labuan Bajo adalah keberadaan Taman Nasional Komodo yang telah dijadikan daya tarik wisata kelas dunia. Labuan Bajo ditetapkan sebagai 10 Bali baru karena potensi alam yang dimilikinya. Kementrian pariwisata menetapkan Labuan Bajo sebgai 10 destinasi prioritas merupakan salah satu strategi pemerintah dalam mendongkrak kunjungan wisatawan. Hal ini dibuktikan dengan meningkatnya kunjungan wisatawan ke Labuan Bajo setiap tahunnya, seperti pada tabel berikut

Tabel 1. Jumlah Kunjungan Wisatawan di Labuan Bajo, Kabupaten Manggarai Barat 2015-2019

\begin{tabular}{l|l|l|l}
\hline No & Tahun & $\begin{array}{l}\text { Jumlah } \\
\text { kunjungan } \\
\text { (orang) }\end{array}$ & $\begin{array}{l}\text { Pertumbuhan } \\
(\%)\end{array}$ \\
\hline 1 & 2015 & 61.257 & $36,7 \%$ \\
\hline 2 & 2016 & 83.712 & $33,5 \%$ \\
\hline 3 & 2017 & 111.749 & $45,8 \%$ \\
\hline 4 & 2018 & 162.9884 & $14,8 \%$ \\
\hline 5 & 2019 & 187.098 & \\
\hline \multicolumn{2}{l}{ Total } & 606.800 & $28 \%$ \\
\hline
\end{tabular}

Sumber: Dinas Pariwisata dan Kebudayaan Manggarai Barat, 2019.

Berdasarkan tabel 1 diketahui bahwa kunjungan wisatawan ke Labuan Bajo, Kabupaten Manggrai Barat selama lima tahun terakhir mengalami peningkatan di rata-rata pertumbuhan 28\%. Meskipun sudah menarik banyak wisatawan, pengembangan pariwisata Labuan Bajo masih memiliki kendala, seperti disampaikan kepala dinas pariwisatata Kabupaten Manggarai Barat Bapak Agustinus Rinus bahwa, Labuan Bajo sebagai pintu masuk ke Taman Nasional Komodo memang direncanakan untuk menjadi wisata premium, namun ada beberapa realita yang menjadi kendala. Misalnya, tawaran atraksi wisata yang masih minim sehingga kunjungan ke Labuan Bajo masih identik dengan hanya melihat komodo. Kemudian pemandangan kurang menarik di beberapa titik penting di Labuan Bajo bertebaran sampah menandakan karakter pariwisata dari masyarakat Labuan Bajo masih kurang. Krisis air minum seringkali terjadi di Labuan Bajo terutama saat musim kemarau. Perkara infrastruktur dan retribusi, yang mengkoneksikan satu tempat ke tempat lain, serta ketersediaan sarana dan prasarana. Sumber daya manusia, konflik agraria atau sengketa lahan dan ketersediaan pusat oleh-oleh atau buah tangan. Hal ini menandakan bahwa ada persoalan mendasar yang harus mendapat penanganan cepat di destinasi pariwisata Labuan Bajo. 
Berdasarkan hal tersebut pengelolaan pariwisata bukanlah sesuatu yang mudah untuk dilaksanakan, karena banyak faktor yang mempengaruhinya. Ada dua sisi yang harus diperhatikan dalam usaha tersebut yaitu wisatawan sebagai pengguna jasa dan pelaku pariwisata ( Masyarakat Lokal, stakeholder dan Pemerintah) sebagai penyedia jasa pariwisatanya. Melihat semua kondisi terkait pelayanan yang diberikan dan disediakan di daya tarik wisata Labuan Bajo, penelitian bermaksud mengetahui faktor pendorong dan penarik wisatawan berkunjung ke Labuan Bajo, Kabupaten Manggrai Barat hasil nantinya akan dijadikan bahan evaluasi dan dasar untuk pengelolaan dan pengembangan pariwisata Labuan Bajo ke depanya, memberikan kontribusi dan tambahan informasi bagi pihak terkait guna pengembangan dan peningkatan kinerja komponen pariwisata Labuan Bajo, Kabupaten Manggarai Barat.

\section{METODE PENELITIAN}

Penelitian ini berlokasi di Labuan Bajo, Kabupaten Manggarai Barat. Secara operasional, variabel yang diteliti adalah motivasi wisatawan berkunjung dari dua sub variabel yaitu; Faktor pendorong dan Faktor penarik. Terdapat dua sub variabel utama yaitu; Faktor pendorong dengan 13 indikator dan Faktor penarik dengan 19 indikator. Di antaranya, melepaskan diri dari rasa jenuh (X1), melepaskan diri dari rutinitas sehari-hari (X2), merasakan relax, segar dan memanjakan diri (X3), penyegaran fisik dan mental (X4), menghabiskan waktu liburan (X5), mencari tempat mewah dan eksklusif (X6), menceritakan pengalaman berkunjung kepada teman atau keluarga (X7), menunjukan eksistensi dengan mengunjungi Pulau Komodo yang mendunia (X8), menghabiskan waktu bersama teman atau keluarga (X9), melakukan interaksi dengan masyarakat lokal (X10), merayakan bulan madu dengan pasangan (X11), menikmati sesuatu yang baru dan menarik (X12), melihat dan mencoba gaya hidup baru dan berbeda (X13), melihat budaya dan tradisi yang berbeda (X14), bangunan bersejarah (X15), mempelajari budaya dan bahasa setempat (X16), pemandangan alam yang indah (X17), udara yang bersih dan sejuk (X18), cuaca yang bersahabat (X19), kelengkapan fasilitas yang mendukung (X20), keamanan dan kebersihan fasilitas di daya tarik wisata (X21), variasi aktivitas wisata yang ada
(X22), berwisata karena ada acara tertentu (X23), daerahnya cocok untuk berpetualang (X24), banyak spot instagramable (sedang populer) (X25), ketersediaan paket wisata di sekitar kawasan wisata (X26), ketersediaan informasi mengenai Labuan Bajo melalui media sosial (X27), kemudahan akses menuju daya tarik wisata (X28), harga masuk ke daya tarik wisata terjangkau (X29), harga makanan dan minuman terjangkau (X30), Harga aktivitas terjangkau (X31) dan harga akomodasi terjangkau (X32). Jenis data yang digunakan adalah data kualitatif dan kuantitatif. Sumber data yaitu data primer dan sekunder. Pengumpulan data dilakukan dengan wawancara, kuesioner dan kepustakaan. Teknik penentuan sampel adalah purposive sampling dengan jumlah sampel 100 orang, menggunakan rumus slovin. Teknik analisis data yang digunakan adalah analisis faktor dengan menggunakan bantuan SPSS versi 23.0 for windows.

\section{HASIL DAN PEMBAHASAN}

\section{Karakteristik Wisatawan yang Berkunjung ke Labuan Bajo, Kabupaten Manggarai Barat}

Hasil kuesioner yang disebarkan kepada 100 orang wisatawan, yang sudah berkunjung ke Labuan Bajo didominasi oleh wisatawan yang berjenis kelamin laki-laki dengan persentase $57 \%$, dengan rentang usia 21-25 tahun (33\%) dan kelompok umur 26-30 (28\%). Daerah asal wisatawan nusantara yang mendominasi adalah Jakarta dengan persentase $16 \%$ dan daerah asal wisatawan mancanegara yang mendominasi adalah negara Gremany dengan persentase $18 \%$.

\section{Uji Validitas dan Reliabilitas}

Uji validitas dilakukan untuk menguji apakah instrument penelitian atau tiap butir kuesioner benar-benar valid. Ketentuan suatu instrument dikatakan valid apabila nilai korelasi r-hitung > r- tabel Sugiyono (2012), dan dikatakan reliabel jika alpha cronbach $\geq 0,6$. Ardana (2016). Hasil penelitian menunjukan dari 13 indikator faktor pendorong dan 19 indikator faktor penarik memiliki nilai r-hitung $>\mathrm{r}$ - tabel $(0,279)$ berdasarkan product moment pearson item kuesioner penelitian dinyatakan valid. Pada uji realibilitas yang telah dilakukan dengan rumus alpha cronbanch, diketahui bahwa seluruh indikator variabel memiliki nilai koefisien alpha yang lebih besar dari 0,6 yaitu 
faktor pendorong 0,602 dan faktor penarik 0,69, dengan demikian indikator dalam kuesioner dinyatakan reliable

\section{Analisis Faktor}

Analisis faktor merupakan independent technique yaitu teknik analisisi multivariate untuk melacak (exploratory) hubungan dari seluruh independent variable (butir item) dengan variabel lainnya.

1. Merumuskan masalah

Teori yang digunakan adalah teori motivasi yang difokuskan pada variabel faktor pendorong dan penarik dari Yuan \& McDonald, 1990 (dalam Lay, 2014). Jumlah variabel utama yang diteliti adalah dua variabel yaitu Faktor pendorong wisatawan yang terdiri dari 13 indikator dan faktor penarik wisatawan yang terdiri dari 19 indikator, dengan jumlah responden 100 orang yang terdiri dari 50 orang wisatawan nusantara dan 50 orang wisatawan mancanegara yang disebarkan dengan menggunakan kuesioner melalui google form.

2. Membuat Matrik Korelasi

Dalam membuat matriks korelasi diidentifikasi variabel-variabel lain sehingga dapat dikeluarkan dari analisisi. Analisis faktor dianggap layak jika besaran $\mathrm{KMO} \geq$ 0,5 dan Uji Measure of Sampling (MSA) yang digunakan untuk mengukur derajat korelasi antara variabel dengan kriteria MSA $\geq 0,5$. Sedangkan tingkat probabilitas $(\mathrm{sig})$ harus lebih kecil atau sama dengan 5\% $(0,05)$.

Tabel 2. Uji KMO dan Bartlett's Test Faktor Pendorong

\begin{tabular}{l|l|l}
\hline \multicolumn{3}{c}{$\begin{array}{c}\text { KMO and Bar } \\
\text { tlett's Test }\end{array}$} \\
\hline $\begin{array}{l}\text { Kaiser-Meyer-Olkin Measure } \\
\text { of Sampling Adequacy }\end{array}$ & .559 \\
\hline \multirow{2}{*}{$\begin{array}{l}\text { Bartlett's Test } \\
\text { of Sphericity }\end{array}$} & $\begin{array}{l}\text { Approx. Chi- } \\
\text { Square }\end{array}$ & 107.638 \\
\cline { 2 - 3 } & Df & 78 \\
\cline { 2 - 3 } & Sig & .015 \\
\hline
\end{tabular}

Sumber: Hasil Penelitian, 2020.

Berdasarkan Tabel dapat dijelaskan bahwa besarnya nilai Kaiser Meyer Olkin $(\mathrm{KMO})=$ 0,559 menunjukan bahwa nilai $\mathrm{KMO}>$ dari 0,50. Bartlett's Test of Sphericity yang diperoleh adalah 107.638 dengan signifikansi 0.015 . Hasil ini menunjukan bahwa antara indikator pada faktor pendrorong wisatawan telah terjadi korelasi (signifikansi<0,05) sehingga model faktor dapat digunakan.

Tabel 3. Uji KMO dan Bartlett's Test Faktor Penarik

\begin{tabular}{l|l|r}
\hline \multicolumn{3}{c}{ KMO and Bartlett's Test } \\
\hline $\begin{array}{l}\text { Kaiser-Meyer-Olkin Measure of } \\
\text { Sampling Adequacy. }\end{array}$ & .619 \\
\hline $\begin{array}{l}\text { Bartlett's Test of } \\
\text { Sphericity }\end{array}$ & $\begin{array}{l}\text { Approx. Chi- } \\
\text { Square }\end{array}$ & 225.463 \\
\cline { 2 - 3 } & Df & 171 \\
\cline { 2 - 3 } & Sig. & .003 \\
\hline
\end{tabular}

Sumber: Hasil Penelitian, 2020.

Berdasarkan Tabel dapat dijelaskan bahwa, besarnya nilai $\mathrm{KMO}=0,619$ menunjukan bahwa nilai KMO lebih besar dari 0,5. Bartlett's Test of Sphericity yang diperoleh adalah 225,463 dengan signifikansi 0.003 . Hasil ini menunjukan bahwa antara indikator pada faktor penarik wisatawan telah terjadi korelasi.(signifikansi $0,05)$, sehingga model faktor dapat digunakan.

Tabel 4. Hasil Uji MSA Faktor Pendorong

\begin{tabular}{|c|c|}
\hline Indikator & Nilai MSA \\
\hline $\begin{array}{l}\text { Melepaskan diri dari rasa jenuh } \\
\text { (X1) }\end{array}$ & 0,627 \\
\hline $\begin{array}{l}\text { Melepaskan diri dari rutinitas } \\
\text { sehari-hari (X2) }\end{array}$ & 0,564 \\
\hline $\begin{array}{l}\text { Merasakan relax, segar dan } \\
\text { memanjakan diri (X3) }\end{array}$ & 0,558 \\
\hline Penyegaran fisik dan mental (X4) & 0,621 \\
\hline Menghabiskan waktu liburan (X5) & 0,598 \\
\hline $\begin{array}{l}\text { Mencari tempat mewah dan } \\
\text { eksklusif (X6) }\end{array}$ & 0,515 \\
\hline $\begin{array}{l}\text { Menceritakan pengalaman } \\
\text { berkunjung kepada keluarga atau } \\
\text { teman (X7) }\end{array}$ & 0,530 \\
\hline $\begin{array}{l}\text { Menunjukan eksistensi dengn } \\
\text { mengunjungi Labuan Bajo yang } \\
\text { mendunia menurut UNESCO (X8) }\end{array}$ & 0,597 \\
\hline $\begin{array}{l}\text { Menghabiskan waktu bersama } \\
\text { teman atau keluarga (X9) }\end{array}$ & 0,512 \\
\hline $\begin{array}{l}\text { Melakukan interaksi dengan } \\
\text { masyarakat lokal (X10) }\end{array}$ & 0,543 \\
\hline $\begin{array}{l}\text { Merayakan bulan madu dengan } \\
\text { pasangan (X11) }\end{array}$ & 0,386 \\
\hline $\begin{array}{l}\text { Menikmati sesuatu yang baru dan } \\
\text { menarik (X12) }\end{array}$ & 0,504 \\
\hline $\begin{array}{l}\text { Melihat dan mencoba gaya hidup } \\
\text { baru dan berbeda (X13) }\end{array}$ & 556 \\
\hline
\end{tabular}

Sumber: Hasil Penelitian, 2020. 
Hasil Uji MSA dari 13 indikator yang diamati dalam model terdapat satu indikator yang tidak memenuhi kriteria yaitu X11, dengan nilai MSA $0,386<0,5$. Maka, indikator ini dikeluarkan dari model, dan tersisa 12 indikator yang memenuhi kriteria.

Tabel 5. Uji MSA Faktor Penarik

\begin{tabular}{|c|c|}
\hline Indikator & $\begin{array}{l}\text { Nilai } \\
\text { MSA }\end{array}$ \\
\hline $\begin{array}{l}\text { Melihat budaya dan tradisi yang } \\
\text { berbeda (X14) }\end{array}$ & 0,620 \\
\hline Bangunan bersejarah (X15) & 0,734 \\
\hline $\begin{array}{l}\text { mempelajari budaya dan Bahasa } \\
\text { setempat (X16) }\end{array}$ & 0,620 \\
\hline $\begin{array}{l}\text { Pemandaangan alam yang indah } \\
\text { (X17) }\end{array}$ & 0,628 \\
\hline Udara yang bersih dan sejuk (X18) & 0,609 \\
\hline Cuaca yang bersahabat (X19) & 0,670 \\
\hline $\begin{array}{l}\text { Kelengkapan fasilitas yang } \\
\text { mendukung (X20) }\end{array}$ & 0,529 \\
\hline $\begin{array}{l}\text { Keamanan dan kebersihan fasilitas di } \\
\text { daya Tarik wisatanya (X21) }\end{array}$ & 0,614 \\
\hline $\begin{array}{l}\text { Variasi aktivitas wisata yang ada } \\
\text { (X22) }\end{array}$ & 0,614 \\
\hline Ada acara tertentu $(\mathrm{X} 23)$ & 0,621 \\
\hline $\begin{array}{l}\text { Tempatnya cocok untuk berpetualang } \\
\text { (X24) }\end{array}$ & 0,689 \\
\hline $\begin{array}{l}\text { Spot instagramable (sedang populer) } \\
\text { (X25) }\end{array}$ & 0,687 \\
\hline $\begin{array}{l}\text { Ketersedian paket wisata disekitar } \\
\text { kawasan wisata (X26) }\end{array}$ & 0,510 \\
\hline $\begin{array}{l}\text { Ketersedian informasi mengenai } \\
\text { Labuan bajo melalui media sosial } \\
\text { (X27) }\end{array}$ & 0,502 \\
\hline $\begin{array}{l}\text { Kemudahan akses menuju ke daya } \\
\text { tarik wisata (X28) }\end{array}$ & 0,526 \\
\hline $\begin{array}{l}\text { Biaya masuk ke daya tarik wisata } \\
\text { yang terjangkau (X29) }\end{array}$ & 0,647 \\
\hline $\begin{array}{l}\text { Harga makanan dan minuman } \\
\text { disekitar kawasan wisata yang } \\
\text { terjangkau (X30) }\end{array}$ & 0,539 \\
\hline Harga aktivitas yang terjagkau (X31) & 0,543 \\
\hline $\begin{array}{l}\text { Harga akomodasi yang terjangkau } \\
\text { (X32) }\end{array}$ & 0,671 \\
\hline
\end{tabular}

Sumber: Hasil Penelitian, 2020.

Hasil uji MSA dari 19 indikator pada faktor penarik yang diamati dalam model telah memenuhi kriteria MSA $\geq 0,5$ yang menunjukan bahwa hubungan antar indkator sangat erat.

1. Menentukan Jumlah Faktor

Penentuan jumlah faktor dilakukan untuk menentukan berapa banyak faktor yang terbentuk mewakili indikator yang diteliti. Penentuan jumlah faktor ini ditentukan berdasarkan pada besarnya nilai eigenvalue dari setiap faktor yang muncul. Faktor utama yang dipilih adalah faktor yang mempunyai nilai eigenvalue $\geq 1$.

Tabel 6. Jumlah Faktor Pendorong

\begin{tabular}{|c|c|c|c|c|c|c|}
\hline \multicolumn{7}{|c|}{ Total Variance Explained } \\
\hline \multirow{2}{*}{$\begin{array}{c}\text { Com } \\
\text { pone } \\
\text { nt }\end{array}$} & \multicolumn{3}{|c|}{ Initial Eigenvalues } & \multicolumn{3}{|c|}{$\begin{array}{l}\text { Extraction Sums of } \\
\text { Squared Loadings }\end{array}$} \\
\hline & Total & $\begin{array}{c}\% \text { of } \\
\text { Varianc } \\
\text { e } \\
\end{array}$ & $\begin{array}{c}\text { Cumula } \\
\text { tive } \%\end{array}$ & Total & $\begin{array}{c}\% \text { of } \\
\text { Varianc } \\
\text { e } \\
\end{array}$ & $\begin{array}{c}\text { Cumula } \\
\text { tive } \%\end{array}$ \\
\hline 1 & 2.029 & 16.912 & 16.912 & 2.029 & 16.912 & 16.912 \\
\hline 2 & 1.514 & 12.618 & 29.530 & 1.514 & 12.618 & 29.530 \\
\hline 3 & 1.466 & 12.219 & 41.749 & 1.466 & 12.219 & 41.749 \\
\hline 4 & 1.126 & 9.380 & 51.128 & 1.126 & 9.380 & 51.128 \\
\hline 5 & .974 & 8.113 & 59.242 & & & \\
\hline 6 & .888 & 7.398 & 66.640 & & & \\
\hline 7 & .862 & 7.186 & 73.826 & & & \\
\hline 8 & .780 & 6.503 & 80.329 & & & \\
\hline 9 & .721 & 6.009 & 86.338 & & & \\
\hline 10 & .637 & 5.312 & 91.650 & & & \\
\hline 11 & .541 & 4.504 & 96.154 & & & \\
\hline 12 & .461 & 3.846 & 100.000 & & & \\
\hline
\end{tabular}

Sumber: Hasil Penelitian, 2020.

Berdasarkan Tabel, dapat diketahui bahwa terdapat empat faktor yang terbentuk dari 12 indikator yang mendorong wisatawan berkunjung ke Labuan Bajo, Kabupaten Manggarai Barat.

Tabel 7. Jumlah Faktor Penarik

\begin{tabular}{l|r|r|r|r|r|r}
\hline \multirow{2}{*}{$\begin{array}{c}\text { Comp } \\
\text { onent }\end{array}$} & \multicolumn{3}{|c|}{ Initial Eigenvalues } & \multicolumn{3}{c}{$\begin{array}{c}\text { Extraction Sums of } \\
\text { Squared Loadings }\end{array}$} \\
\cline { 2 - 7 } & Total & $\begin{array}{c}\text { \% of } \\
\text { Varianc } \\
\text { e }\end{array}$ & $\begin{array}{c}\text { Cumula } \\
\text { tive \% }\end{array}$ & Total & $\begin{array}{c}\text { \% of } \\
\text { Varianc } \\
\text { e }\end{array}$ & $\begin{array}{c}\text { Cumula } \\
\text { tive \% }\end{array}$ \\
\hline 1 & 2.554 & 13.441 & 13.441 & 2.554 & 13.441 & 13.441 \\
\hline 2 & 1.965 & 10.340 & 23.781 & 1.965 & 10.340 & 23.781 \\
\hline 3 & 1.598 & 8.411 & 32.192 & 1.598 & 8.411 & 32.192 \\
\hline 4 & 1.427 & 7.511 & 39.703 & 1.427 & 7.511 & 39.703 \\
\hline 5 & 1.358 & 7.147 & 46.850 & 1.358 & 7.147 & 46.850 \\
\hline 6 & 1.149 & 6.048 & 52.897 & 1.149 & 6.048 & 52.897 \\
\hline 7 & 1.049 & 5.521 & 58.419 & 1.049 & 5.521 & 58.419 \\
\hline 8 & .964 & 5.076 & 63.495 & & & \\
\hline 9 & .847 & 4.456 & 67.951 & & & \\
\hline 10 & .819 & 4.310 & 72.261 & & & \\
\hline 11 & .793 & 4.176 & 76.437 & & & \\
\hline 12 & .717 & 3.775 & 80.212 & & & \\
\hline 13 & .642 & 3.380 & 83.592 & & & \\
\hline 15 & .612 & 3.221 & 86.813 & & & \\
\hline 16 & .585 & 3.077 & 89.890 & & & \\
\hline 17 & .533 & 2.806 & 92.696 & & & \\
\hline 18 & .491 & 2.583 & 95.279 & & & \\
\hline 19 & .477 & 2.509 & 97.788 & & & \\
\hline
\end{tabular}

Sumber: Hasil Penelitian, 2020.

Berdasarkan Tabel dapat diketahui bahwa dari 19 indikator yang memenuhi kriteria terbentuk 7 faktor baru yang menarik wisatawan berkunjung ke Labuan Bajo, Kabupaten Manggarai Barat. 
1. Rotasi Faktor

Rotasi Faktor merupakan langkah yang dilakukan untuk menyederhanakan matrik faktor. Matrik faktor yang terbentuk masih harus diidentifikasi lebih lanjut, sehingga perlu dilakukan rotasi faktor untuk mengetahui hasil yang lebih terstruktur dan lebih sederhana menggunakan metode varimax

Tabel 8. Rotasi Faktor Pendorong

\begin{tabular}{|c|c|c|c|c|}
\hline \multicolumn{5}{|c|}{ Rotated Component Matrix ${ }^{\mathrm{a}}$} \\
\hline & \multicolumn{4}{|c|}{ Component } \\
\hline & 1 & 2 & 3 & 4 \\
\hline $\mathrm{X} 1$ & .683 & .043 & .170 & -.092 \\
\hline $\mathrm{X} 2$ & .620 & .289 & .149 & -.122 \\
\hline $\mathrm{X} 3$ & .559 & .117 & -.176 & .329 \\
\hline $\mathrm{X} 4$ & 238 & .615 & -.044 & .015 \\
\hline $\mathrm{X} 5$ & 243 & .124 & .190 & .673 \\
\hline $\mathrm{X} 6$ & -.157 & -.010 & -.150 & .726 \\
\hline $\mathrm{X} 7$ & .021 & .264 & .713 & -.208 \\
\hline $\mathrm{X} 8$ & -.229 & .598 & .353 & .239 \\
\hline $\mathrm{X} 9$ & .207 & -.080 & .708 & -.053 \\
\hline $\mathrm{X} 10$ & .557 & -.401 & .027 & .161 \\
\hline $\mathrm{X} 12$ & -.010 & -.145 & .523 & .160 \\
\hline X13 & .065 & .691 & -.119 & .029 \\
\hline
\end{tabular}

Sumber: Hasil Penelitian, 2020.

Berdasarkan tabel 8 dapat diketahui bahwa faktor pendorong wisatawan dengan 12 indikator yang telah dirotasi semuanya memenuhi kriteria dengan nilai loading factor lebih dari 0,5 , diantaranya; faktor pertama terdiri atas X1 (berwisata karena ingin melepaskan diri dari rasa jenuh), X2 (Berwisata Karena ingin melepaskan diri dari rutinitas sehari-hari),X3 (Berwisata karena ingin meraakan relax, segar dan memanjakan diri) dan X10 (Berwisata untuk melakukan interaksi dengan masyarakat lokal). Faktor kedua terdiri atas; X4 (Berwisata untuk penyegaran fisik dan mental),X8 (Berwisata untuk menunjukan eksistensi dengan mengunjungi Labuan Bajo yang mendunia menurut UNESCO) dan X13 (Berwisata untuk melihat dan mencoba gaya hidup baru dan berbeda). Faktor ketiga yang terdiri atas; X7 (Berwisata untuk menceritakan pengalaman berkunjung kepada teman atau keluarga), X9 (Berwisata untuk menghabiskan waktu bersama teman) dan X12 (Berwisata untuk menikmati sesuatu yang baru dan menarik) dan faktor keempat terdiri atas; X5 (Berwisata untuk menghabiskan waktu liburan) dan X6 (Berwisata untuk mencari tempat mewah dan eksklusif).
Tabel 9. Rotasi Faktor Penarik

\begin{tabular}{|c|c|c|c|c|c|c|c|}
\hline \multicolumn{8}{|c|}{ Rotated Component Matrix ${ }^{\mathrm{a}}$} \\
\hline & \multicolumn{7}{|c|}{ Component } \\
\hline & 1 & 2 & 3 & 4 & 5 & 6 & 7 \\
\hline$\overline{X 14}$ & -.052 & .316 & .298 & .105 & .141 & -.617 & .023 \\
\hline$\overline{X 15}$ & .047 & .324 & .447 & .057 & .228 & -.050 & .158 \\
\hline $\mathrm{X} 16$ & .044 & .807 & -.022 & .032 & .058 & .038 & .085 \\
\hline $\mathrm{X} 17$ & .682 & -.101 & -.076 & -.076 & -.194 & -.237 & -.089 \\
\hline $\mathrm{X} 18$ & .206 & .176 & .049 & .224 & -.263 & .071 & .631 \\
\hline $\mathrm{X} 19$ & .616 & .025 & -.061 & .168 & .052 & 402 & .106 \\
\hline $\bar{X} 20$ & .051 & .141 & -.147 & .747 & -.203 & .005 & .046 \\
\hline $\mathrm{X} 21$ & -.142 & .125 & .073 & -.168 & .165 & -.106 & .708 \\
\hline $\mathrm{X} 22$ & .386 & -.431 & .091 & .032 & .076 & -.029 & .429 \\
\hline $\mathrm{X} 23$ & -.143 & .618 & .011 & .131 & -.191 & -.284 & .088 \\
\hline $\mathrm{X} 24$ & .408 & -.121 & -.279 & .245 & -.092 & -.140 & .006 \\
\hline $\mathrm{X} 25$ & .718 & -.005 & -.032 & -.107 & .179 & .040 & .033 \\
\hline $\mathrm{X} 26$ & 149 & .060 & .062 & .028 & .747 & .050 & .008 \\
\hline $\mathrm{X} 27$ & -.156 & -.147 & -.283 & .495 & .230 & .237 & .408 \\
\hline $\mathrm{X} 28$ & -.018 & .017 & .410 & .655 & .254 & -.106 & -.164 \\
\hline $\mathrm{X} 29$ & .416 & .126 & .095 & .090 & -.562 & .204 & -.051 \\
\hline$\overline{X 30}$ & -.094 & .074 & .365 & .028 & .026 & .707 & -.040 \\
\hline $\mathrm{X} 31$ & -.181 & -.206 & .775 & -.061 & -.198 & .079 & .029 \\
\hline X32 & -.089 & .463 & 446 & -136 & .284 & 114 & .082 \\
\hline
\end{tabular}

Sumber: Hasil Penelitian, 2020.

Berdasarkan Tabel 9 dapat diketahui bahwa faktor penarik wisatawan dari 19 indikator yang telah dirotasi, terdapat 12 indikator yang memenuhi kriteria, dan 7 indikator tidak memenuhi kriteria. Ketujuh indikator yang tidak memenuhi kriteria ini memiliki nilai loading factor tidak mencapai 0,5 , yaitu indikator X14 (Berwisata melihat budaya dan tradisi yang berbeda),X15 (Berwisata karena bangunan bersejarah), X22 (Berwisata karena variasi aktivitas yang ada) ,X24 (berwisata karena tempatnya cocok untuk berpetualang) ,X27 (Berwisata karena ketersediaan informasi mengenai Labuan Bajo melalui media sosial), X29 (Berwisata karena biaya masuk ke daya tarik wisata terjangkau) dan X32 (Berwisata karena harga akomodasi terjangkau). Sedangkan indikator yang memenuhi kriteria membentuk 7 faktor baru di antaranya: faktor pertama terdiri atas X17 (Berwisata karena pemandangan alam yang indah), X19 (Berwisata karena cuaca yang bersahabat) dan X25 (Berwisata karena banyak spot instagramable (sedang populer). Faktor kedua terdiri atas; X16 (Berwisata karena ingin mempelajari budaya dan bahasa setempat) dan X23 (Berwisata karena ada evnt-event tertentu). Faktor ketiga yaitu X31 (Berwisata karena aktivitas yang terjangkau). Faktor keempat terdiri atas; X20 (Berwisata karena kelengkapan 
fasilitas yang mendukung) dan X28 (Berwisata karena kemudahan akses menuju daya tarik wisata) . Faktor kelima yaitu X26 (Berwisata karena ketersedian paket wisata disekitar kawasan wisata). Faktor keenem yaitu X30 (Berwisata karena harga makanan dan minuman di sekitar kawasan yang terjangkau) dan Faktor ketujuh terdiri atas X18 (Berwisata karena udara yang bersih dan sejuk) dan X21 (Berwisata karena keamanan dan kebersihan fasilitas di daya tarik wisatanya).

\section{Interpretasi Faktor}

Interpretasi faktor dapat dilakukan dengan mengelompokan variabel yang memiliki loading factor (korelasi antara variabel dengan faktor yang terbentuk). Maka dapat djelaskan bahwa semakin tinggi loading factor maka semakin erat juga hubungan antara indikator dengan faktor tersebut. Interpretasi faktor berfungsi untuk mengelompokan indikator yang memiliki nilai loading factor minimal 0,5 , sementara indikator yang memiliki loading factor kurang dari 0,5 akan dikeluarkan dari model

Tabel 10. Faktor Pendorong Baru Wisatawan

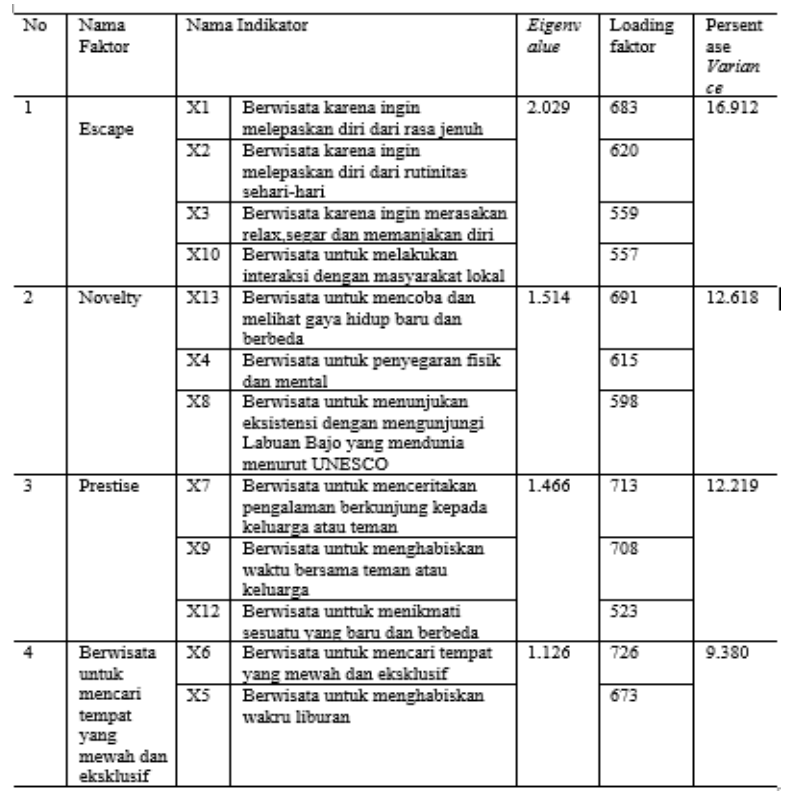

Sumber: Hasil Penelitian, 2020.

Faktor yang terbentuk diberi nama sesuai dengan variabel yang telah dikelompokan, yang dapat diuraikan sebagai berikut

a. Faktor escape, penamaan faktor escape dikarenakan salah satu indikator pada sub variabel escape memiliki nilai loading factor tertinggi yakini 683 dengan eigenvalue sebesar 2.029 dan total variance sebesar $16.912 \%$.

b. Faktor Novelty, penamaan faktor novelty dikarenakan salah satu indikator pada sub variabel novelty memiliki nilai loading factor tertinggi yakni 691 dengan eigenvalue sebesar 1.514 dan total variance sebesar $12.618 \%$

c. Faktor Prestige, penamaan faktor prestige dikarenakan salah satu faktor pada sub variabel prestige memiliki loading factor tertinggi yakni 713 dengan eigenvalue sebesar 1.466 dan total variance sebesar 12 . $219 \%$

d. Faktor mencari tempat mewah dan eksklusif, karena memiliki nilai loading factor tertinggi yakni 726 dengan eigenvalue sebesar 1.126 dan total variance sebesar $9.380 \%$

Tabel 11. Faktor Penarik Baru Wisatawan

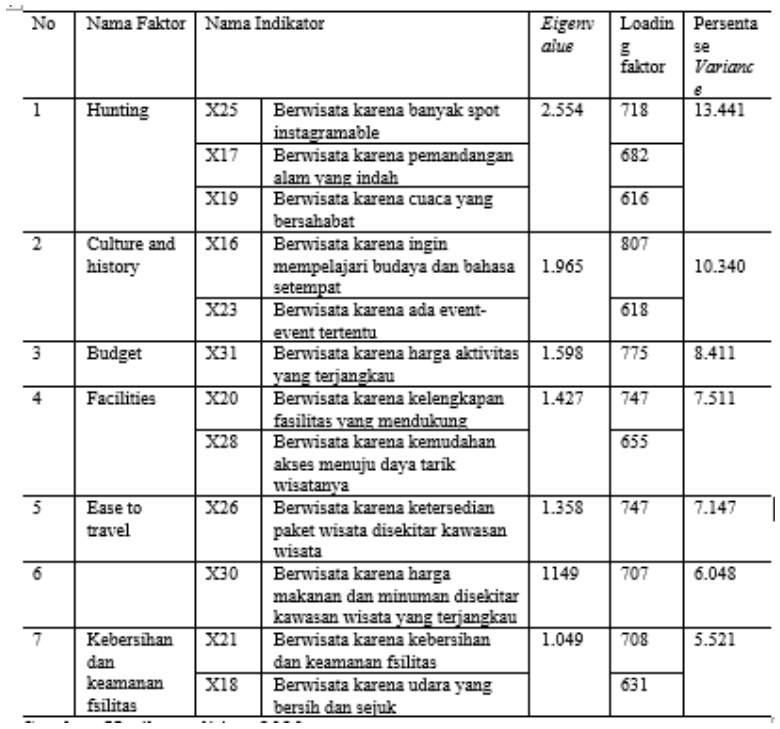

Sumber: Hasil Penelitian, 2020.

Faktor yang terbentuk diberi nama sesuai dengan variabel yang telah dikelompokan, yang dapat diuraikan sebagai berikut

a. Faktor Hunting, pemberian nama faktor hunting dikarenakan salah satu indikator pada sub variabel hunting yakni banyak spot instagramable memiliki nilai loading factor tertinggi yaitu 718 dengan eigenvalue sebesar 2.554 dan total variance sebesar $13.441 \%$

b. Faktor Culture and History, penamaan faktor ini disebabkan karena salah satu indikator pada sub variabel culture and history yakni berwisata karena ingin mempelajari budaya dan bahasa setempat memiliki nilai loading fator tertinggi yaitu 807 dengan loading 
factor sebesar 1.965 dan total varaiance sebesar $10.340 \%$

c. Faktor Budget, penamaan faktor budget dikarenakan salah satu indikator pada sub variabel budget yakni harga aktivitas yang terjangkau memiliki nilai loading factoe tertinggi yaitu 775 dengan eigenvalue sebesar 1.598 dan total variance sebesar $8.411 \%$

d. Faktor Facilities, penamaan faktor facilities dikarenakan indikator pada sub variabel facilities memiliki nilai loading factor tertinggi yaitu 747 dengan eigenvalue sebesar 1.427 dan total variance sebesar $7.511 \%$

e. Ease to travel, diberi nama Faktor ease to travel dikarenakan salah satu indikator pada sub-variabel Ease to Travel yaitu berwisata karena ketersedian paket wisata disekitar kawasan wisata, memiliki nilai loading factor tertinggi yakni 747 dengan eigenvalue sebesar 1.358 dan total variance sebesar $7.147 \%$.

f. Harga makanan dan minuman terjangkau, diberi nama faktor ini karena memiliki nilai loading factor tertinggi yakni 707 dengan eigenvalue sebesar 1.149 dan total variance sebesar $6.048 \%$.

g. Kebersihan dan keamanan fasilitas, Faktor ketujuh diberi nama Faktor ini karena memiliki nilai loading factor tertinggi yakni 708 dengan eigenvalue sebesar 1.049 dan total variance sebesar $5.521 \%$.

\section{Faktor pendorong dan penarik wisatawan berkunjung ke Labuan Bajo, Kabupaten Manggarai Barat}

Hasil analisis faktor menunjukan bahwa dari 13 indikator tersebut satu indikator dinyatakan tidak memenuhi kriteria uji MSA sehingga dikeluarkan dari model penelitian. Kemudian 12 indikator tersisa menghasilkan empat faktor baru yang mendorong wisatawan berkunjung ke Labuan Bajo, Kabupaten Manggarai Barat. Adapun hasil faktor pendorong baru wisatawan tersebut dapat diuraikan sebagai berikut

Faktor pertama yaitu Escape terdiri atas empat indikator, yaitu; 1) berwisata karena ingin melepaskan diri dari rasa jenuh, sebelum melakukan perjalanan wisata, wisatawan akan mencari referensi tentang destinasi yang dikunjungi. wisatawan melakuakn perjalanan wisata dengan mencari suasana baru diluar tempat tinggalnya untuk melepaskan rasa jenuhnnya dari aktivitas keseharian. Potensi wisata alam dan keunikan Labuan Bajolah menjadi salah satu tempat yang cocok melepaskan rasa jenuh. 2) berwisata karena ingin melepaskan diri dari rutinitas sehari-hari, keadaan hiruk pikuk suasana perkotaan dan aktivitas yang padat menyebakan wisatawan nusantara melakukan perjalanan wisata dan memilih Labuan Bajo sebagai destinasi wisatanya. Ini disebabkan keadaan alam yang asri menjadi tempat yang cocok untuk wisatawan memanjakan diri dengan keindahan yang ditawarkan Labuan Bajo.3) berwisata karena ingin merasakan relax, segar dan memanjakan diri kekayaan alama yang dimiliki Labuan Bajo mampu menciptakan suasana yang sejuk dan segar sehingga cocok untuk wisatawan merelaksasikan pikiran, memanjakan diri. 4) berwisata untuk melakukan interaksi dengan masyarakat lokal, wisatawan berkunjung ke Labuan Bajo selain karena salah satu daya tarik wisatannya yang mendunia yaitu Pulau Komodo, wisatawan juga dapat berinteraksi dengan masyarakat lokal

Faktor kedua yaitu Novelty terdiri atas tiga indikator, diantaranya; 1) berwisata untuk penyegaran fisik dan mental, selain mengunjungi pulau komodo, wisatawan mancanegara juga akan disuguhkan ragam panorama indah, padang sabana dan perbukitan, sehingga wisatawan bisa bersantai serta memanjakan diri dengan pemandangan yang indah tersebut untuk menyegarkan fisik maupun mental. 2) berwisata untuk melihat dan mencoba gaya hidup baru dan berbeda, kehidupan serta keadaan lingkungan wisatawan didaerah asalnya dengan kehidupan dan keadaan lingkungan di kawasan wisata Labuan Bajo tentunya sangat berbeda seperti kemacetan, kegiatan perindustrian serta jumlah penduduk yang padat, perbedaan inilah yang menjadikan segala sesuatu dialami oleh wisatawan saat berwisata ke Labuan Bajo merupakan hal yang baru. Wisatawan yang berkunjung ke Labuan Bajo disamping menikmati keindahan alam, mereka juga melihat rutinitas atau keseharian masyarakat di sekitar kawasan wisata. Misalnya didaya tarik wisata Liang dara setiap wisatawan yang berkunjung akan mengenakan selendang songke (selendang tenunan), towe songke (sarung adat) serta bagi wisatawan laki-laki akan mengenakan sapu (destar). Selain itu ada beberapa hasil tenunan daerah yang dijarit kemudian digunakan sebagai baju dalam ajang Putri Indonesia tahun 2020, para finalis menggunakan beberapa hasil tenunan Flores saat berwisata ke Labuan Bajo. Ini merupakan suatu 
trend atau gaya baru bagi mereka. 3) berwisata untuk menunjukan eksistensi dapat mengunjungi Labuan Bajo yang mendunia menurut UNESCO. Ini berhubungan dengan faktor meningkatkan harga diri. Mengunjungi Labuan Bajo yang mendunia adalah salah satu pengakuan diri bagi wisatawan, serta menjadi suatu kebanggaan dan kepuasan tersendiri bagi mereka dengan prestasi yang dimiliki daya tarik wisata Labauan Bajo, diantaranya; menjadi salah satu dari 4 destinasi prioritas, sebagai wisata super premium dan eksklusif yang ditetapkan oleh Presiden RI Bapak Joko Widodo serta menjadi salah satu dari 10 destinasi Bali Baru, ditambah lagi dengan salah satu daya tariknya yang menjadi brand dunia yaitu Komodo (Komodo Florensiensi), di tetapkan oleh New7Wonders pada tanggal 12 November 2011 menjadi salah satu 7 keajaiban dunia

Faktor ketiga faktor prestige relaksasi terdiri atas tiga indikator, di antaranya; 1) berwisata untuk menceritakan pengalaman berkunjung kepada keluarga atau teman. Hal ini berkaitan dengan teori motivasi oleh Ryan (1999) yang menjelaskan bahwa mengunjungi destinasi menunjukan kelas atau gaya hidup, menunjukan eksistensi atau gengsi juga merupakan dorongan yang dapat meningkatkan status atau drajat sosial. Dengan mengunjungi daya tarik wisata Labuan Bajo yang sedang populer dengan potensi serta ketetapan pemerintah menjadikan Labuan Bajo sebagai destinasi super prioritas dan premium, menceritakan pengalaman berkunjung baik secara langsung maupun tidak (melalui unggahan di media sosial) ke Labuan Bajo menunjukan eksistensi atau gengsi wisatawan kepada keluarga atau temannya. 2) berwisata untuk menghabiskan waktu bersama keluarga atau teman, 3) berwisata untuk menikmati sesuatu yang baru, wisatawan melakukan perjalanan wisata untuk mendapatkan suasana yang baru dan menarik di daerah tujuan wisata

Faktor keempat yaitu faktor mencari tempat mewah dan eksklusif, diantaranya; 1) berwisata untuk mencari tempat mewah dan eksklusif, segala bentuk pelayanan dan fasilitas dikawasan wisata Labuan Bajo, keindahan dan keunikan yang dimilikinya diantaranya keindahan dibawa lautnya yang menjadikannya tempat snorkeling terbaik setelah Raja Ampat di Papua, menungguli Galapagos Amerika Serikat, Menurut CNN, pantai merah menjadi salah satu dari 7 di dunia, Pulau Komodo yang menjadi 7 keajaiban dunia menurut organisasi
New7Wonders pada tanggal 12 November 2011 serta garis pantai yang membentuk daratan dan lautan Labuan Bajo, serta kebijakan pemerintah dalam mengembangkan Kawasan Strategis Pariwisata Nasional (KSPN). 2) berwisata untuk menghabiskan waktu liburan, untuk memanfaatkan waktu liburan, begitupula dengan wisatawan mancanegara yang melakukan perjalanan wisata pada musim liburan.

Hasil analisis menyatakan bahwa dari 19 indikator menarik wisatawan yang terdapat 7 indikator yang tidak memenuhi kriteria MSA dan 12 indikator yang memenuhi kriteria. Kemudian indikator yang memenuhi kriteria tersebut membentuk 7 faktor baru yang menarik wisatawan berkunjung ke Labuan Bajo Kabupaten Manggarai Barat. Adapun hasil faktor penarik wisatawan tersebut dapat diuraikan sebagai berikut

Faktor pertama yaitu Hunting, yakni dijabarkan perindikatornya: 1) berwisata karena spot instagramable, Labuan Bajo akhir-akhir ini menjadi destinasi pilihan public figure terkenal dari nusantara diantaranya Ruben Onsu, Anang Hermansya, Raffi Ahmad, Bunga Citra Lestari, Nia Rhamadani, Maia Estianty dan Ayu Tingting, (dikutip darikompasiana.com) serta public figure dari mancanegara diantaranya, pemain sepak bola Arjen Robben, Pembalap Morot GP Valntinoan Rossi dan pemain bola Zaltan Ibrahimovich. Dengan mempostingan beberapa foto di daya tarik wisata Labuan Bajo. Adanya infuluancer tersebut dapat menarik wisatawan berkunjung ke Labuan Bajo, Kabupaten Manggarai Barat. 2) berwisata karena pemandangan alam yang indah, menjadi keptutsan yang tepat jika wisatawan berkunjung karena tertarik dengan pemandangan alam yang indah Labuan Bajo. 3) berwisata karena cuaca yang bersahabat, Kabupaten Manggarai Barat beriklim tropis, pada bulan Juni sampai dengan September arus angin berasal dari Australia dan tidak banyak mengandung uap air sehingga mengakibatkan musim kemerau. Sebaliknya pada bulan Desember sampai Maret arus angin berasal dari Asia dan Samudera Pasifik yang menyebabkan musim hujan. Walau demikian mengingat Manggarai Barat dekat dengan Australia arus anging mengandung uap air dari Asia dan Samudra Pasifik sampai di wilayah Manggarai kandungan airnya sudah berkurang yang mengakibatkan hari hujan di Manggarai Barat lebih sedikit dibandingkan dengan wilayah yang lebih dekat denga Asia. Hal ini menjadikan Manggarai Barat sebagai wilyah yang tergolong 
kering dimana hanya 4 bulan (Januari sampai Maret dengan Desember) yang relatif basah dan 8 bulan sisanya relatif kering. Sehingga dengan cuaca yang seperti ini wisatawan manncanegara memiliki waktu yang banyak untuk berkunjung ke Labuan Bajo, Kabupaten Managgarai Barat. (manggarai.co.id)

Faktor kedua yaitu culture and history terdiri atas dua indikator. 1) berwisata karena ingin mempelajari budaya dan bahasa setempat, hal ini berkaitan erat dengan teori motivasi oleh McIntos (1977), Murphy (1985) dan Sharpley 1994 (dalam Pitana dan Gayatri 2005:59) yang mengelompokan motivasi menjadi 4 kelompok besar dan salah satunya culture motivation. Wisatawan yang berkunjung ke Labuan Bajo tertarik dengan budaya dan tradisi orang Manggarai. Hal ini dibuktikan dengan terlibatnya wisatawan (bule) pada beberapa acara besar masyarakat lokal seperti 'penti' (ucapan syukur hasil panen), mengenakan baju adat Manggarai saat berwisata ke beberapa daya tarik wisata di Desa Liang Ndara serta menggunakan bahasa manggarai saat berkomunikasi, seperti "enu" saapan untuk cewek dan "nana" sapaan untuk laki-laki. 2) Berwisata karena ada acara tertentu, acara internasional yang diselenggarakan di Labuan Bajo yaitu Tour De Flores pada tahun memiliki multifire effect diantaranya meningkatnya kunjungan wisatwan.

Faktor ketiga yaitu budget, terdiri atas satu indikator. Berwisata karena harga aktivitas yang terjangkau. Alasan menyebabkan faktor ini menjadi faktor yang menarik wisatawan berkunjung ke Labuan Bajo, Kabupaten Manggarai Barat. Berdasarkan brand image destinasi sebagai wisata populer dan salah satu daya tarik andalannya yang menjadi warisan dunia yaitu komodo versi UNESCO.

Faktor keempat yaitu facilities terdiri atas dua indikator 1) Berwisata karena kelengkapan fasilitas yang mendukung Labuan Bajo sebagai destinasi super prioritas. Pemerintah terus mendukung pembangunan dan fasilitas dengan meluncurkan beberapa program diantaranya Labuan Bajo rebound dengan protokol CHSE (Cleanliness, Health, Safety and Environmental Sustainability). Lingkup kegiatan meliputi penguatan satpa pesona, revitalisasi amenitas dengan pengadaan barang pendukung CHSE, alat penunjang keamanan serta bimbingan teknis soal 3A (Atraksi, Aksesibilitas dan Amenitas). Presiden Joko Widodo mendukung pengembangan kawasan wisata Labuhan Bajo dengan percepatan pembangunan infrastruktur pendukung pariwisata, seperti pengembangan bandara di daerah tersebut, Pemerintah juga menyiapkan terminal multifungsi di daerah Wae Kelambu, Manggarai Barat, Labuan Bajo. Terminal multifungsi tersebut nantinya akan memisahkan aktivitas pariwisata dan bongkar muat peti kemas di Pelabuhan Labuan Bajo. Dengan dibangunnya terminal multifungsi tersebut nantinya Pelabuhan Labuan Bajo akan dikhususkan bagi kapal-kapal wisatawan yang akan bersandar dan berkunjung ke daerah itu. Presiden mengunjungi Labuan Bajo untuk melakukan percepatan pembangunan infrastruktur pariwisata di daerah tersebut. Kala itu, Kepala Negara memastikan akan melakukan penataan total di daerah Labuan Bajo agar menjadi semakin menarik bagi wisatawan. Salah satu penataan tersebut ialah mengenai pelabuhan khusus logistik yang akan dipersiapkan dan dipisahkan dari aktivitas di Pelabuhan Labuan Bajo. 2) Berwisata karena kemudahan akses menuju ke daya tarik wisatanya, akses saat berwisata ke Labuan Bajo tidak sesulit seperti yang dibayangkan, yang mungkin dalam pemikiran orang-orang Labuan Bajo adalah salah satu daya tarik wisata yang ada dibagaian Timur jadi akses menuju kesana agak susah. Kenyataanya akses menuju Labuan Bajo sangatlah mudah dengan peresmian Bandara Komodo sebagai Bandara Internasional oleh Presiden RI Bapak Joko Widodo pada 27 Desember tahun 2015 yang mana pembangunan ini memudahkan akses wisatawan untuk berkunjung ke Labuan Bajo termasuk penerbangan internasional serta dibukannya rute penerbangan baru pada tahun 2019 yaitu LBJ JKT, LBJ - SBY dan LBJ - LOP. Kemudian untuk menuju daya tari wisatanya cukuplah mudah, jarak antara bandara dengan pelabuhan sebagai central point menuju daya tarik wisata seperti Taman Nasional Komodo hanya ditempuh 10 menit bagi wisatawa yang memilih overseas tour, kemudian dari pelabuhan Bajo wisatawan menggunakan perahu menuju pulau yang mana sebagain besar daya tarik wisata Labuan Bajo berada di pulau seperti Pulu Komodo,Pulau Rinca,Pulau Padar, Pantai Pink, Pulau Kanawa dan lainnya dan untuk wisatawan yang memilih overland tour di Bandara sudah tersedia bus dan taxi yang dikelola oleh travel agent.

Faktor kelima yaitu faktor ease to travel terdiri dari satu indikator yaitu berwisata karena ketersediaan paket wisata disekitar kawasan 
wisata. Beberapa alasan menyebabkan faktor ini menjadi faktor yang menarik wisatawan berkunjung ke Labuan Bajo, Kabupaten Manggarai Barat, yakni saat wisatawan nusantara berkunjung ke Labuan Bajo tidak akan mengalami kesulitan saat mencari paket wisata karena paket wisata tersedia sudah tersedia di online travel agent serta offline travel agent seperti tourist informasi yang tersedia mulai dari Bandara Komodo hingga menuju ke hotel anda akan temukan touris informasi disepanjang jalannya.

Faktor keenem yakni faktor Harga makanan dan minuman yang terjangkau. Beberapa alasan menyebabkan faktor ini menjadi faktor yang menarik wisatawan nusantara berkunjung ke Labuan Bajo, Kabupaten Manggarai Barat, yaitu Tentunya, tidak cukup kalau eksplor satu kota baru tanpa mencoba kulinernya. Di Labuan Bajo, wisatawan bisa menikmati makanan khas Flores ataupun makanan autentik negara lain, sambil memanjakan mata dengan panorama alam yang indah. Labuan Bajo dikenal dengan pesona baharinya dan tentu saja komodo yang langka. Tapi selain itu, kuliner setempat seperti aneka olahan seafood patut untuk dicoba. Wisata kuliner cocok sekali dilakukan sore atau malam hari setelah menjelajah perairan sekitar Labuan Bajo. Salah satu lokasi yang asyik buat mencicipi kuliner setempat adalah Kampung Ujung. Letaknya strategis, bisa dicapai dengan jalan kaki dari pelabuhan dan naik ojek sekitar 10 menit saja dari Bandara Komodo. Lokasinya outdoor di pesisir Labuan Bajo, dengan gerobakgerobak pedagang yang berjejer, haragnyapun cukup bervariasi dari 20 ribu hingga 50.000 per orangnya, dengan harga yang relatif cukup murah wisatawan bisa langsung merasakan ikan segar yang ditangkap oleh warga sekitar

Faktor ketujuh yaitu kebersihan dan keamanan fasilitas faktor kelengkapan fasilitas yang mendukung. yakni dijabarkan perindikatornya; 1) Berwisata karena keamanan dan kebersihan fasilitas di daya tarik wisatanya, dalam mendukung Labuan Bajo sebagai destinasi super prioritas pemerintas terus mendukung pembangunan dan fasilitas dengan meluncurkan beberapa program diantaranya Labuan Bajo rebound dengan menerapkan protokol CHSE (Cleanliness, Health, Safety and Environmental Sustainability) di berbagai destinasi dengan lingkup kegiatan meliputi penguatan satpa pesona, revitalisasi amenitas dengan pengadaan barang pendukung CHSE dan alat penunjang keamanan serta bimbingan teknis soal 3A (Atraksi, Aksesibilitas dan Amenitas). Dengan beberapa bentuk kegiatan tersebut diatas wisatawan nusantara yang berkunjung ke Labuan Bajo akan merasa aman dengan fasilitas dan kebersihan disetiap destinasi wisatanya. 2) Berwisata karena udara yang bersih dan sejuk, kegiatan Pembangunan di Kabupaten Manggarai Barat khususnya Labauan Bajo masih terhitung kurang, hal ini dibuktikan dengan tidak adanya bangunan tinggi, kegiatan pertambangan dan bahkan industi-industri manufaktur lainnya. Sekarang pemerintah hanya mefokuskan pada pada satu titik yaitu pengembangan industri pariwisata, sehingga udara yang dihasilkan masih bersih dan sejuk

\section{Faktor dominan yang mendorong dan menarik wisatawan berkunjung ke Labuan Bajo Kabupaten Manggrai Barat}

Hasil analisis faktor pendorong wisatawan diperoleh empat faktor yang terbentuk dari 12 indikator sebagai indikator yang mendorong wisatawan nusantara berkunjung ke Labuan Bajo, Kabupaten Manggarai Barat. Faktor yang terbentuk adalah faktor escape (16.912\%), novelty $(12,618 \%)$, prestige $(12.219 \%)$ dan mencari tempat mewah dan eksklusif $(9.380 \%)$. Keempat faktor tersebut, faktor yang dominan dalam memberikan kontribusi mendorong wisatawan nusantaara berkunjung ke Labuan Bajo, Kabupaten Manggarai Barat adalah faktor dengan nilai eigenvalue tertinggi. Berdasarkan eigenvalue tertinggi maka faktor dominan yang mendorong wisatawan berkunjung ke Labuan Bajo adalah faktor escape dengan eigenvalue 2.029 dengan keberagaman indikator sebesar $16.912 \%$. Faktor ini terdiri atas 4 indikator yang mendorong wisatawan berkunjung ke Labuan Bajo, Kabupaten Manggarai Barat. empat (4) indikator tersebut terdiri dari (1) Berwisata karena ingin melepaskan diri dari rasa jenuh dengan loading factor 683, (2) Berwisata karena ingin melepaskan diri dari rutinitas sehari-hari dengan loading factor sebesar 620, (3) Berwisata karena ingin merasakan relax, segar dan memanjakan diri dengan loading factor 559 dan (10) Berwisata untuk melakukan interaksi dengan masyarakat lokal dengan loading factor 557.

Hasil analisis faktor diperoleh tujuh faktor penarik wisatawan yang dari 19 indikator yang awalnya ditetapkan sebagai indikator penarik wisatawan berkunjung ke Labuan Bajo, Kabupaten Manggarai Barat. Faktor yang 
terbentuk adalah faktor hunting (13.441\%), culture and history (10.340\%), Budget (8.411), facilities (7.511), ease to travel (7.147), harga makanan dan minuman terjangkau (6.048) dan kebersihan dan keamanan fasilitas (5.521). Faktor dominan dalam memberikan kontribusi menarik wisatawan berkunjung ke Labuan Bajo, Kabupaten Manggarai Barat adalah faktor yang terbentuk dengan nilai eigenvalue tertinggi dari ketujuh faktor terbentuk. Berdasarkan eigenvalue tertinggi maka faktor dominan yang menarik wisatawan nusantara berkunjung ke Labuan Bajo Kabupaten Manggarai Barat adalah faktor hunting dengan eigenvalue 2.554 dengan keberagaman indikator sebesar $13.441 \%$. Faktor ini terdiri dari 3 indikator yang menarik wisatawan berkunjung ke Labuan Bajo, Kabupaten Manggarai Barat. Indikator tersebut adalah (1) Berwisata karena banyak spot instagramable (sedang populer) dengan loading factor 718, (2) Berwisata karena pemandangan alam yang indah dengan loading factor 682 dan (3) Berwisata karena cuaca yang bersahabat dengan loading factor 616

\section{SIMPULAN DAN SARAN Simpulan}

Berdasarkan hasil analisis terkait faktor pendorong dan penarik wisatawan berkunjung ke Labuan Bajo Kabupaten Manggarai Barat, maka dapat disimpulkan bahwa terdapat emapt faktor yang mendorong wisatawan untuk berkunjung diantaranya 1) faktor escape, 2) faktor novelty, 3) faktor prestige dan faktor tempat mewah dan eksklusif dengan faktor dominan yang mendorong adalah faktor escape dengan eigenvalue sebesar 2.029 dan keberagaman variabel sebesar $16.912 \%$. Analisis faktor penarik wisatawan menghasilkan 7 faktor baru yang mendorong wisatawan berkunjung ke Labuan Bajo Kabupaten Manggrai Barat, yaitu; 1) Hunting, 2) Culture and history, 3) Budget, 4) Facilities, 5) Ease to tavel, 6) Harga makanan dan minuman terjangkau dan 7) Kebersihan dan keamanan fasilitas dengan faktor dominan yang menarik wisatawan adalah faktor hunting dengan eigenvalue sebesar 2.554 dengan keberagaman indikator sebesar $13.441 \%$.

\section{Saran}

Dari hasil penelitian yang dilakukan peneliti, terdapat saran yang dapat diberikan yaitu sebagai berikut:

1. Agar tetap menjaga dan mempertahankan faktor yang mendorong wisatawan nusantara maupun wisatawan mancanegara dan faktor penarik wisatawan nusantara maupun wisatawan mancanegara yang berkunjung ke daya tarik wisata Labuan Bajo, Kabupaten Manggarai Barat. Pemerintah dan Pengelola juga harus memperhatikan beberapa indikator yang memiliki nilai eingenvalue rendah untuk memperbaiki sesuai apa uang diharapkan wisatawan

2. Akan lebih baik jika pemerintah dan pengelola pariwisata Labuan Bajo Kabuapten Manggarai Barat menambah variasi aktivitas diantaranya; adanya wisata cycling dikarenakannya banyaknya perbukitan yang bisa dimanfaatkan sebagai jalur cycling, adanya wisata malam seperti club dan cafe agar lama berkunjung (lenght of stay) dari wisatawan lebih lama.

3. Akan lebih baik jika pemerintah dan pengelola meningkatkan pembangunan perhotelan yang lebih memadai sesuai dengan permintaan wisatawan

4. Akan lebih baik jika disediakan pusat perbelanjaan khas oleh-oleh

5. Untuk peneliti selanjutnya perlu dilakukan penelitian tentang motivasi dan minat berkunjung ulang wisatawan. Untuk mengetahui seberapa besar ketertarikan wisatawan terhadap daya tarik wisata Labuan Bajo serta seberapa besar minat mereka berkunjung. 


\section{Kepustakaan}

Ardana, C., \& Lukman, H. (2016). Sistem Informasi Akutansi. Jakarta: Mitra Wacana.

Bagyono. (2014). Pariwisata dan Perhotelan. Bandung: Alfabeta.

Cooper et. al. 1993.Tourism Principles \&Practice.England : LongmanGroup Limited

Dinas Pariwisata Dan Kebudayaan Manggarai Barat. 2019. Data Kunjungan Wisatawan Labuan Bajo.

Ghozali, Imam. 2009. Aplikasi Analisis Multivariate Dengan Program SPSS. Edisi Keempat. Semarang: Badan Penerbit Universitas Diponegoro.

Kotler, Philip Dan Kevin Lane Keller. 2009. Manajemen Pemasaran. Edisi 13 Jilid satu. Erlangga : Jakarta.

Kotler, Philip.2011. Manajemen Pemasaran di Indonesia : Analisis, Perencanaan, Implementasi dan Pengendalian. Jakarta :Salemba Empat

Manik, G., Suwena, K., \& Suardana , W. (2016). Faktor Pendorong Dan Penarik Wisatawan Backpacker Mancanegara Berwisata Ke Bali . Jurnal Ipta, 15-20.

McIntosh. 1977. Karakteristik Wisatawan. Yogyakarta. Andi.

Sugiyono. (2015). Metode Penelitian Kombinasi (Mix Methods). Bandung: Alfabeta.

Suwena, I Ketut dan I Gst Ngr Widyatmaja. 2017. Pengetahuan Dasar Ilmu Pariwisata. Denpasar : Pustaka Larasan.

Suwena, Widyatmaja, 2010. Pengetahuan Dasar Ilmu Pariwisata. Denpasar : UdayanaUniversity Press

Indonesia, W. (2018, 24 september). 10 Bali Baru Diperkenalkan ke Selandia Baru Lewat Sales Mission. Diakses pada 24 februari 2020, dari kemenparekraf.go.id: http://www.kemenparekraf.go.id/post/ne ws-10-bali-baru-diperkenalkan-keselandia-baru-lewat-sales-mission 